\title{
Cross-order comparisons using indexes of cerebral development
}

\author{
WILLIAM I. RIDDELL, KENNETH CORL, and FREDERICK GRAVETTER \\ State University of New York, College at Brockport, Brockport, New York 14420
}

\begin{abstract}
Three pacas were tested on a series of extradimensional shift problems to evaluate the relationship between learning ability and indexes of cerebral development. The paca was chosen because this particular rodent has a cerebral index which far exceeds most other rodents, and, in fact, is very similar to primitive primates. The results indicated that, if one controls for species-specific abilities, the performance of the paca is what one would expect given the paca's brain index. The results were interpreted as suggesting that cross-order comparisons might be reasonable along a brain index continuum.
\end{abstract}

Recently Riddell, Gravetter, and Rogers (1976) have proposed that, if controls are instituted for problem difficulty within species, the degree of inhibitory control possessed by different species is correlated with indexes of cerebral development. The data, which were presented on six different groups, indicate that this relationship extends across orders, in that tree shrews (Primates) were similar to rats (Rodentia), both behaviorally and in cerebral development, and inferior to the other primates tested. While the above ordering is certainly not surprising, there are species of large brained rodents whose cerebral indexes exceed that of the more primitive primates, and therefore should show greater inhibitory control.

In order to directly test this hypothesis, the present study tested pacas [a large brained rodent $(30 \mathrm{~g})$ ] using the identical task and procedures employed with other species. If the paca performs at a level superior to the shrews, and in fact closer to squirrel monkeys, this result would support the notion that continuums based on cerebral development might well be generalizable across mammalian orders. If, on the other hand, pacas, while being superior to the rats, still are markedly inferior to what would be expected for primates (given this level of cerebral development), this result would be consonant with the suggestion that cerebral continua are only useful within orders.

Although there are many measures of cerebral development available, Jerison's $(1963,1973)$ index, i.e., $\mathrm{N}_{\mathrm{c}}$, was employed in the present study in order to be consistent with the previous work reported by Riddell et al. (1976). $N_{c}$ is basically a measure of the number of cortical neurons a species possesses above the amount that would be expected to be necessary to maintain primitive functioning.

\section{METHOD}

\section{Subjects}

The subjects were three adult female pacas. The pacas were housed together in an $8 \times 8 \times 8 \mathrm{ft}$ chain link cage and had free access to food and water. They were kept on a standard diet of guinea pig chow, Omalene, Monkey 25, and lettuce leaves. A $5 \mathrm{~g}$ piece of apple served as a reinforcer. It should be noted that these large rodents $(6,000 \mathrm{gr})$ are excellent laboratory animals, since they are not only extremely docile and easy to maintain but they also shape in the operant chamber considerably quicker than laboratory rats. $\mathrm{N}_{\mathrm{c}}$ for the paca was determined by taking the mean index calculated from the subjects in the present study and averaging this datum with the index calculated from the values presented by von Bonin (1937).

\section{Apparatus}

The test chamber employed was identical to that used previously with squirrel monkeys, except the foodcup was removed, allowing the apple section to drop directly onto the floor of the chamber. The apparatus consisted of a $61 \times 42 \times 61 \mathrm{~cm}$ solid test chamber that had a $23-\mathrm{cm}$-square stimulus panel located $21 \mathrm{~cm}$ from the cage floor. The stimulus panel contained two $4.5-\mathrm{cm}$-diam wells, spaced $10 \mathrm{~cm}$ apart, and located $2.5 \mathrm{~cm}$ up from the bottom of the panel. Each well was capable of being illuminated via a back light illumination panel. The subjects' responses were recorded by photocells located behind the wells and in front of the illumination panel.

\section{Procedure}

As was the case with the apparatus, the procedure was identical to that employed with rats, tree shrews, squirrel monkeys, capuchins, children, and college students (Riddell et al., 1976). During the initial training sessions, both stimulus wells were either illuminated or unilluminated for each trial. A 5-sec ITI was employed between trials, during which time the wells were again either both illuminated or unilluminated on a random schedule. Any response during the ITI reset the 5 -sec interval. During this phase of training, any trial response resulted in reinforcement. This phase of pretraining was continued until a subject made 30 trial responses during a $15-$ min period, with no more than $60 \%$ of the responses to any one side. On the day following criterial performance in this condition, discrimination training began.

A random series (restricted so that no more than three successive trials were identical and, within successive blocks of 10 trials, each condition appeared equally often) was employed to illuminate one of the two stimulus wells for each of the 30 noncorrection trials that comprised a daily session. During discrimination training, the stimulus wells were unilluminated during the ITI. Training was continued on a discrimination until a subject achieved at least $90 \%$ correct within a daily session. On 
Table 1

Mean Brain Indexes and Performance Data on Pacas and Other Species Tested on This Task

\begin{tabular}{|c|c|c|c|c|c|c|c|c|c|}
\hline Species & $\mathrm{N}_{\mathrm{c}} \times 10^{7}$ & $\mathrm{~K}$ & $P_{1}$ & $\mathrm{~B}_{2}$ & $\mathbf{P}_{3}$ & $\mathrm{~B}_{1}$ & $\mathrm{P}_{2}$ & $B_{3}$ & Total \\
\hline Rats & 2.4 & 56.37 & 49.6 & 68.5 & 64.2 & 71.0 & 69.8 & 49.5 & 379 \\
\hline Shrews & 10.1 & 57.56 & 47.0 & 189.0 & 71.0 & 49.0 & 103.0 & 46.0 & 505 \\
\hline Pacas & 37.9 & 38.00 & 21.0 & 184.0 & 38.0 & 390.0 & 45.0 & 38.0 & 716 \\
\hline Squirrel Monkeys & 53.0 & 26.81 & 19.0 & 111.0 & 37.0 & 27.0 & 68.0 & 20.0 & 282 \\
\hline Cebus & 108.9 & 25.79 & 127.0 & 30.0 & 75.0 & 2.0 & 469.0 & 9.0 & 712 \\
\hline Man & 855.6 & 1.19 & 6.0 & 6.0 & 2.0 & 1.0 & 15.0 & 1.0 & 31 \\
\hline
\end{tabular}

the day following criterion performance, a new discrimination problem was initiated. Each of the three subjects was initially tested on a series of three problems, where Problem 1 was identical to Problem 3. The two different discriminations involved were brightness $($ on $=$ positive $)$ and position (right $=$ positive). The ordering of problems for this first sequence was brightness, then position, then brightness, or B1-P2-B3. Ten months following completion of Sequence 1, each subject was tested on a second sequence beginning with position, then brightness, then position, or P1-B2-P3. For each discrimination in each sequence, one of the two stimulus wells was illuminated; the presentation of the stimulus conditions and the recording of responses was all done automatically.

\section{RESULTS}

The mean number of errors made by each species on both Sequence 1 and Sequence 2 are shown in Table 1. As is readily apparent from Table 1 , total errors is not correlated with $\mathrm{N}_{\mathrm{c}}$. In fact, the data yield a Spearman rho of -.31 , which indicates that there is little or no relationship between total errors and brain index. It was just such an unreasonable pattern of results that led Riddell et al. (1976) to suggest that an adequate measure of species learning ability can be obtained only when the raw error scores are adjusted by taking into account relative task difficulty. The proposed adjustment involves solving the following simultaneous equations:

$$
\begin{array}{r}
\mathrm{B}_{\mathrm{on}_{3}} \text { Errors }=\mathrm{K}\left(\mathrm{B}_{2}-\mathrm{B}_{3}\right) /\left(\mathrm{P}_{2}-\mathrm{P}_{3}\right)^{\alpha} \\
\mathrm{P}_{\mathrm{r}_{3}} \text { Errors }=\mathrm{K}\left(\mathrm{P}_{2}-\mathrm{P}_{3}\right) /\left(\mathrm{B}_{2}-\mathrm{B}_{3}\right)^{\alpha}
\end{array}
$$

for each species to obtain a value of $\mathrm{K}$, which is a measure of general species ability uncontaminated by special abilities, for the particular discriminations involved in this paradigm.

Of critical interest in the present investigation is the performance of the pacas on Sequence 2, since the proposed analysis employs $B_{o n_{2}}-B_{o_{n}}$ and $P_{r_{2}}-P_{r_{3}}$ as indicants of the difficulty of learning the brightness and position discrimination, respectively. Since the scores of 184 on the $B_{\text {on }_{2}}$ problem and 38 on $P_{r_{3}}$ are what would be expected in the absence of repeated testing, the Sequence 2 data were handled as if these subjects comprised an independent group. Analysis of the error scores for each species via the techniques proposed by Riddell et al. (1976), which are designed to control for initial species differences, yielded the $\mathrm{K}$ values shown in
Figure 1 . It should be initially noted that only a weak correlation exists (rho $=+.37$ ) between $K$ and total errors a result which supports the notion that $\mathrm{K}$ is an indicant of factors other than special abilities. As can be readily seen from Figure 1, the $\mathrm{K}$ value for the paca (38) is what would be expected from the index of cerebral development, since, on both the brain index and the behavioral measure, pacas fall between tree shrews and squirrel monkeys. From Figure 1 it appears that there is almost a linear $\log$ relationship ( $\mathrm{rho}=-.94$ ) between $\mathrm{N}_{\mathrm{c}}$ and $\mathrm{K}$. The only inversion occurred at low $\mathrm{N}_{\mathrm{c}}$ values, a point at which a basement affect may be evident on this particular dependent measure.

\section{DISCUSSION}

While the addition of any one species which confirms a trend established previously on five different species is certainly not conclusive concerning the proposed relationship between indexes of cerebral development and behavior, the unintuitive nature of the present result adds considerable support to the relationship. The present result suggests that, while the different mammalian orders have been following distinct evolutionary courses for millions of years, a relatively crude measure of cerebral development is capable of ordering the species from different orders. If this type of cross-order overlap is evident between order species, it suggests that $\mathrm{N}_{\mathrm{c}}$ and $\mathrm{K}$ are truly measuring some quality that is over and above those specific morphological adaptations to the specific ecological niches of different species.

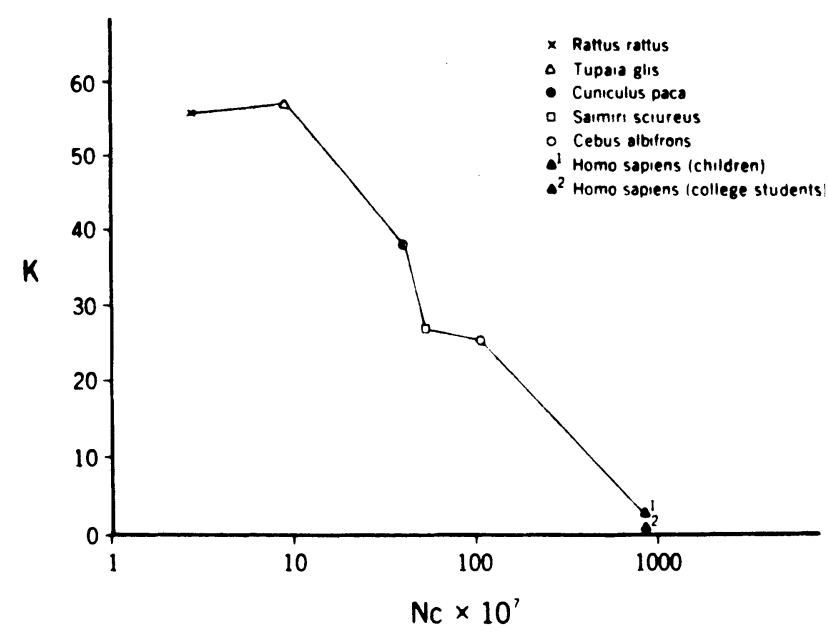

Figure 1. $\mathrm{K}$ as a function of $\mathrm{N}_{\mathrm{c}} \times 10^{7}$ for all species. 


\section{REFERENCES}

JERISON. H. J. Interpreting the evolution of the brain. Human Biology, 1963, 35, 263-291.

JERISON. H. J. Evolution of the brain and intelligence. New York: Academic Press, 1973.

Riddell, W. I., Gravetter, F., \& Rogers, W. Further investigation of the relationship between brain indices and learning. Physiology and Behavior, 1976, in press.

von Bonin, G. Brain weight and body weight in mammals. Journal of General Psychology, 1937, 16, 379-389.

(Received for publication March 21, 1976.) 